\title{
Conversations about measurement and evaluation in impact investing
}

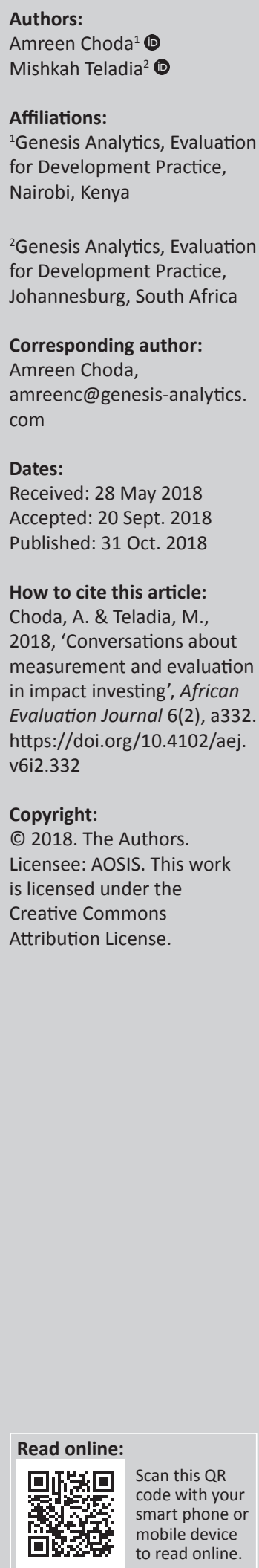

In response to the enduring social, economic and environmental challenges facing the African continent and its population, development interventions are evolving to embrace new approaches, new partnerships and new means of achieving impact. One such area of heightened innovation and growing activity is impact investing. Impact investing is defined as investments made with the intention of generating both financial return and social or environmental impact. As this momentum in impact investing grows, a complementary area of activity has started to put down roots in Africa - social impact measurement.

Genesis Analytics curated and managed the Innovations in Evaluation strand at the recent African Evaluation Association Conference, convened in Uganda in March 2017. This strand was supported by the Rockefeller Foundation and aimed to ignite conversations between impact investment stakeholders and evaluators focused on the African experience with social impact measurement.

This article presents themes emerging from the presentations and conversations within the Innovations in Evaluation strand. The article begins with a brief explanation of the rise of impact investing, globally and within Africa, and then goes on to explain the structure of the Innovations in Evaluation strand. This strand included small group discussions and a think tank, which enabled sharing of ideas and experiences between strand participants. The article, therefore, documents the issues emerging during these discussions, including exploration of the concept of impact measurement and how this understanding differs across stakeholders, the currency of impact measurement and emerging practice.

The article concludes with presenting what stakeholders and evaluators need to jointly explore to ensure that the African experience is well represented as the impact measurement movement continues to gain momentum globally.

\section{Introduction}

The 2017 African Evaluation Association (AfrEA) Conference's theme centred on the 'Evaluation of the Sustainable Development Goals (SDGs): Opportunities and Challenges for Africa'. Genesis Analytics, supported by the Rockefeller Foundation, curated the Innovations in Evaluation strand at the conference, which aimed to explore the emergence of social impact measurement, as well as to facilitate dialogue between evaluators, investors and other practitioners working within impact investing.

The challenges on the African continent have been exacerbated by multiple crises: widespread unemployment, political instability, food insecurity and natural disasters resulting from increasing climate change. While these challenges have persisted for multiple decades, development interventions, over time, have become more cognisant of this complexity. As a result, the nature of poverty alleviation interventions across Africa often involves multiple components, multiple levels of implementation, multiple implementing agencies with multiple agendas and long causal chains with many intermediate outcomes. As a result, the complexity of evaluating such interventions is being increasingly acknowledged by members of the evaluation community, and hence there is more frequent engagement with systems thinking and complexity theory.

In addition, development interventions have evolved to embrace new approaches, new partnerships and new means of achieving impact (KPMG International 2016). One such area of heightened innovation and growing activity is impact investing. As this momentum in impact investing grows, a complementary area of activity has started to put down roots in Africa - social impact measurement. 
The Innovations in Evaluation strand at the 8th AfrEA Conference ${ }^{1}$ brought together cutting-edge ideas from across the globe to allow for collaborative learning opportunities to deepen evaluative thinking and practices owing to the challenges faced by the African continent. The strand focused on innovations in evaluation across two main areas: Substrand 1 - New Forces in Development and Substrand 2 - New Frontiers in Evaluation Methodology. This article concentrates on the former, specifically discussions around impact investing and social impact measurement.

The New Forces in Development substrand highlighted the emergence of impact investing in Africa and how this new trend combines market forces with social goals in a traditional 'developmental' context. Financing the ambitious new global development agenda of the SDGs requires a significant increase in resources; further, the mobilisation of the required resources is far beyond what could be allocated via development assistance (IDEAS 2017). According to the United Nations Conference on Trade and Development, between $\$ 5$ and $\$ 7$ trillion is needed to achieve the SDGs, with an investment gap in developing countries of about $\$ 2.5$ trillion (Niculescu 2017). Hence, the relevance of a discussion around impact investing is highly topical, as impact investing represents one such example of how private capital is leveraged to address the finance required to move the needle on the social and environmental challenges experienced today (Reisman \& Olazabal 2016).

Moreover, over the last decade, the role of the private sector, the value of systemic impact and the potential of impact investing have deepened in importance. While these developments are by no means new, there is a growing recognition that despite the need for measurement and evaluation within these kinds of interventions, conventional evaluation approaches are slow to respond (Innovations for Poverty Action n.d.).

As the impact investing landscape in Africa evolves and matures, it is accompanied by increasing diversity of instruments in use and market players involved. Through this maturation process, there is still further growth needed for social impact measurement that is creative, nimble and 'fit for purpose'. This offers opportunities for evaluators to begin to explore African perspectives and experiences with social impact measurement. A discussion on impact investing, hybrid funds, co-mingling funds, social impact bonds and public-private partnerships (PPPs) brought attention to how these new forces are entirely compatible and complementary. Through four parallel sessions, participants explored impact investing, complexity, market systems innovation and PPPs, as well as the measurement and evaluation of these approaches.

This article begins by defining impact investing and describing the currency of social impact measurement and why it is deservedly receiving increased attention, both globally and in Africa. The article then documents the discussions that were had within the Innovations in Evaluation strand, focusing on emerging themes and providing examples of organisations practising these new methods of impact measurement. The article also presents an argument on the need for client-centricity with an example that hones in on the need for giving respect to those who provide data for impact measurement. Finally, this article concludes by discussing what needs to be further explored in order to facilitate the continued growth of social impact measurement in Africa.

\section{The rise of impact investing}

As a result of mounting social challenges in today's world, coupled with dwindling public funds, new and innovative approaches are needed to address social and environmental challenges (OECD 2015). The responsibility to contribute to social and environmental outcomes no longer falls solely on traditional government, philanthropic and non-governmental actors (Social Impact Investment Taskforce 2014). Impact investing is the term that was coined for a new wave of private socially beneficial financing in the year 2007 through the gathering of investors and thought leaders. These investments are made with the intention of generating both financial return and social or environmental impact (Reisman \& Olazabal 2016).

Within impact investing, non-traditional market players, such as impact investors, are investing in companies, organisations and funds with the intention to generate social and environmental impact alongside a financial return. It is helpful to look at impact investing and its relationship to both traditional investing and traditional philanthropy in the context of a two-by-two matrix, along the dimensions of financial return and social impact (Figure 1).

Impact investing solutions include the use of financing mechanisms to mobilise private sector capital in new and more efficient ways for projects to create a more resilient and inclusive world. They are not meant to replace but rather to complement traditional resource flows such as aid, foreign

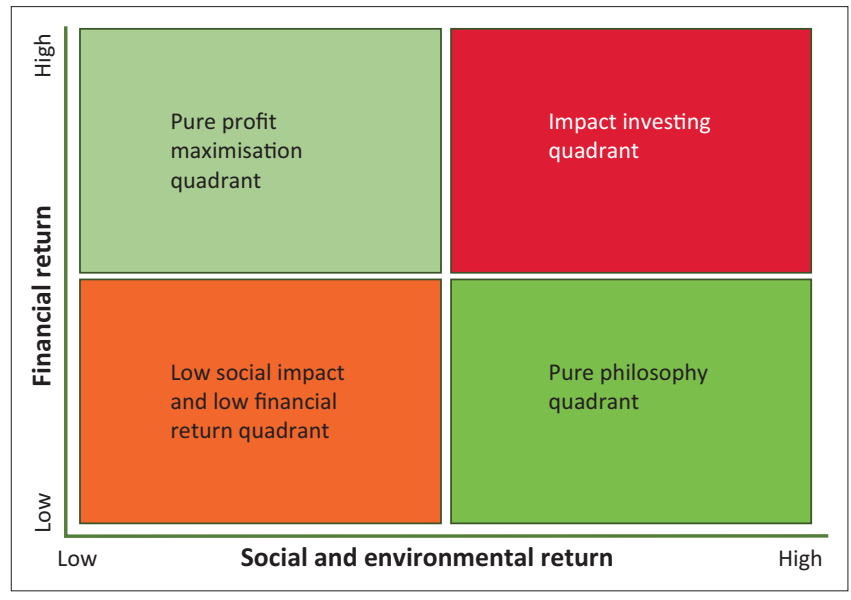

Source: Seitz, T., 2018, The spectrum of impact investing, viewed 23 May 2018, from https:// medium.com/impact-engine/the-spectrum-of-impact-investing-e34b0e4dc164

FIGURE 1: Impact investing in the context of desired outcomes. 


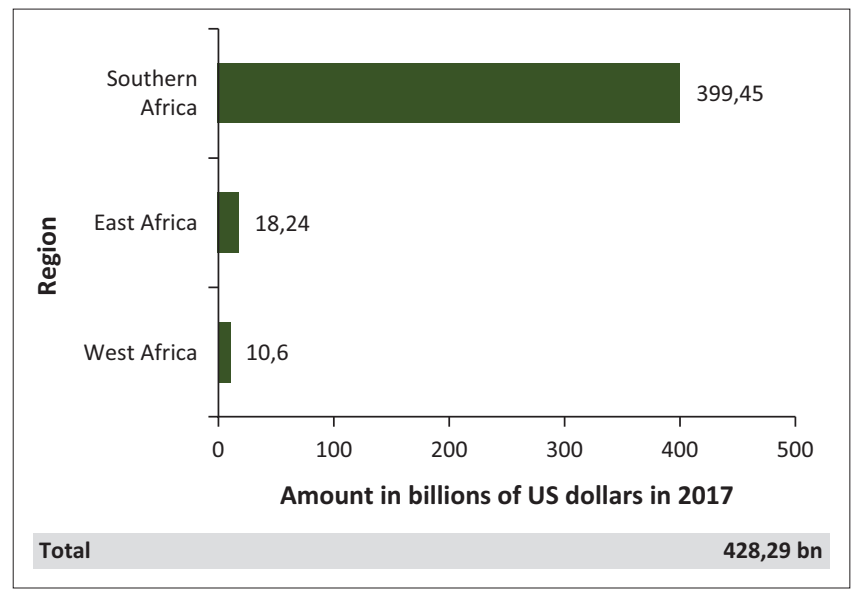

Source: Graduate School of Business, 2018, Responsible investors channel over $\$ 400$ billion into Africa, University of Cape Town, viewed 27 May 2018, from http://www.gsb.uct.ac.za/ po-impact-investing-barometer

FIGURE 2: Total pool of funds directed to impact investing in Africa.

direct investment and remittances. Impact investing therefore has the ability to mobilise the additional resources needed for eliminating poverty, raising living standards and protecting the environment.

In the last decade and across the globe, there has been an exponential increase in the number of impact investors and the pool of funds available for social impact. In Africa, impact investment as a practice remains nascent, and as the total pool of funds available for social impact continues to rise, it is beginning to significantly contribute to the continent's economic growth and development objectives (United Nations Development Programme 2016). According to the latest data from the 2017 African Investing for Impact Barometer, there has been an increase of $23 \%$ and $18 \%$ in Southern Africa and East Africa, respectively, in the pool of funds available compared to the previous year (Graduate School of Business 2018). Research conducted by the Global Impact Investing Network (GIIN) ${ }^{2}$ found that the agriculture and financial services sectors in East Africa; the financial services, infrastructure and energy sectors in Southern Africa; and the energy, FinTech and agriculture sectors in West Africa are those in which impact investing was most active in the years 2015, 2016 and 2015, respectively (GIIN 2015a); (GIIN 2016); (GIIN 2015b).

In the financial year of 2017 , over $\$ 400$ billion in financial assets were directed to investing for impact across Southern Africa, East Africa and West Africa (Figure 2).

\section{Social impact measurement and its currency}

As the volumes for impact investing have grown over time, discussions about the importance of social performance measurement alongside financial indicators have accelerated (Rockefeller Foundation 2012). While there is no common language to date on social impact measurement (European Union \& OECD 2015), we refer to the concept as the 2.https://thegiin.org/ measurement of the social, economic and environmental changes that have been generated through impact investing. While the practice of impact investing is more than 10 years old, the measurement approaches are not well developed and remain fraught with multiple methodological and implementation challenges (Tuan 2008). Therefore, social impact measurement continues to remain an important consideration for both investors and investees, as well as for the legitimacy of the field of impact investing (The New Media Group n.d.). The measurement discussion has been fuelled by the controversy of corporate social responsibility campaigns across the impact investing sector in particular. While many companies have been quick in printing glossy reports on their social return to society, real social impact based on good measurement practices has lagged behind (Lynch 2015).

Industry observers So and Staskevicius amplified the need to strengthen the measurement of impact investing when they stated:

We believe that informal, inconsistent, and weak impact measurement methods could be a real constraint to the growth of the impact investing sector and its prospects to create real social change ... we also believe that the term 'impact investing' runs the risk of being diluted and used as a marketing tool if a certain level of rigor in impact measurement is not established in the industry. (So \& Staskevicius 2015)

The increase in the volume of funds available for social impact also indicates the growing importance of the impact investing market because of its unprecedented focus on impact measurement amongst non-traditional market players. This focus is based on the recognition that there is a need to understand the financial and social return on these investments; because impact investing is a relatively new industry, data on activity and performance can play an important role in developing and growing the industry (OECD 2015).

Moreover, just like traditional approaches to measuring financial performance, it is imperative for impact investors to measure their social impact rigorously. Social impact measurement is important for the legitimacy and advancement of the field of impact investing: not only will rigorous measurement allow the organisations to understand the impact of their work against the social and environmental goals they set, as a means of holding themselves accountable towards those goals, but it is also needed to allow the organisation to utilise this data to drive value creation at the level of the investee, the investor (and their boards) and the broader market (Mudaliar et al. 2017).

In addition to this, social impact measurement is needed for improved investment management amongst existing investors and to attract new investors (McCreless et al. 2014). Social impact measurement can also serve as a conduit for aligning incentives amongst impact investing stakeholders, including dialogue facilitation between investors, businesses 
and affected groups in society (employees, consumers, small businesses inter alia) towards improved performance of impact investing (Social Impact Investment Taskforce 2014).

The impacting investing community has made significant strides towards developing tools for assessing social impact (Bannick \& Goldman 2012). Efforts such as the Global Impact Investment Rating System (GIIRS) ${ }^{3}$ and IRIS ${ }^{4}$ give impact investors a taxonomy to benchmark how firm-level outputs contribute to social change (Bannick \& Goldman 2012). For example, a healthcare provider is able to record the number of patients treated and what the outcomes of that treatment are. Those results can then be compared to others in the field. Despite important progress and growth of market solutions for achieving social and environmental impact in recent years, globally, the adoption of and commitment to these methodologies amongst impact investors remains limited and insufficient (The New Media Group n.d.). Additionally, the sector's measurement practices that assess impact and contribute to an evidence base remain focused at the output level (Reeder et al. 2015) and are applied with limited evaluative thinking, that is, they do not focus on how change happens but rather limit their focus to whether change is happening (Wilson 2016).

The current practice of social impact measurement is extremely varied and further complicated by a myriad of approaches, methods and tools, reflecting the diverse needs of stakeholders (Costa \& Pesci 2016). The MaRS Centre for Impact Investing positions some of the different social impact metrics along what they colloquially call the 'stages of a theory of change' (Vaca \& Dhillon 2016) (Figure 3).

In order to capitalise on the currency of social impact measurement, there is a need to bridge the gap between investors and development practitioners or evaluators where the ideas from each of these fields can be shared with one another. These ideas can then be adapted and contextualised to be useful and take impact investing to the next level, where not only can impact be measured but investments can be targeted effectively and appropriately.

\section{Themes emerging from the Innovations in Evaluation strand The what, why and how of social impact
measurement}

Broadly, impact measurement is concerned with collecting, analysing and communicating the environmental and social impact of an impact investment. However, in line with the literature on social impact measurement, it has become clear that the conceptual definition of impact differs between stakeholder groups (Maas \& Liket n.d.). For instance, for some stakeholders (generally investors seeking to gather evidence that accounts for the impact of their investments),

3.GiIRS conducts third-party assessments of the social and environmental impact of companies and funds.

4.IRIS metrics are designed to measure the social, environmental and financia performance of an investment for a particular focus (https://iris.thegiin.org/)

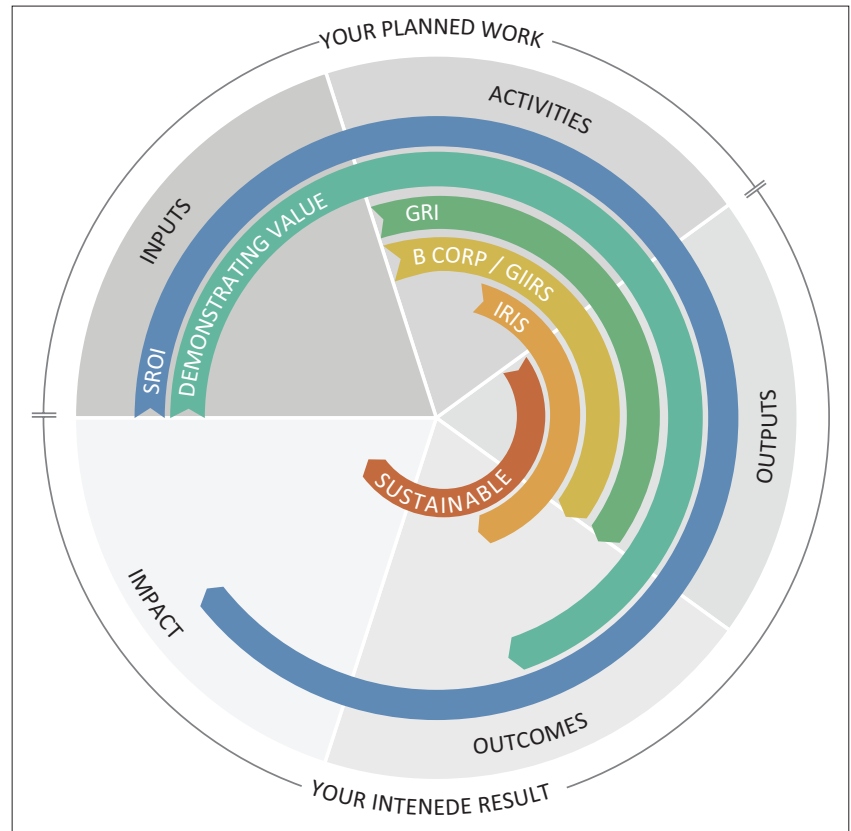

Source: Vaca, S. \& Dhillon, L., 2016, 'Innovations in presenting theory of change', in Evaluation 2016 conference, Atlanta, GA, October 24-29, 2016, viewed n.d., from http:// www.saravaca.com/wp-content/uploads/2016/12/Presenting-ToC-Lovely-Dhillon-SaraVaca-2016.pdf

SROI, social return on investment; GRI, global reporting initiative; GIIRS, global impact investing rating system; IRIS, is a set of standardised metrics that can be used to measure and describe the social, environmental, and financial performance of organisations and businesses receiving impact investment capital.

FIGURE 3: How social impact measurement tools and methods fit into a theory of change.

impact is the direct change that has occurred. This kind of impact might be considered to be the production of outputs. For instance, an investment in solar energy lamps might enable young students to study for longer periods of time at night. Investors would be interested in the number of solar lamps sold and capture a few anecdotal stories of how children could study more hours or breathe clean air. In contrast, evaluators would look to measure a result that provides information on the 'so what' to answer questions around why (and potentially how) the solar energy lamps make a difference in young students' lives. Therefore, a strong theme emerging from the Innovations in Evaluation strand is that the conceptual understanding of impact differs considerably between stakeholders working within impact investment, as well as between these stakeholders and evaluators.

Despite these differences in the definition of impact between stakeholder groups, there is considerable agreement amongst them that it is important to measure impact. A case in point is that, when the Aspen Network of Development Entrepreneurs (ANDE) $)^{5,6}$ started in 2009, there was very little evidence to prove that investment in small and growing businesses (SGBs) would contribute to breaking the cycle of poverty, discussed in the section "The value proposition of social impact measurement for small and growing businesses'. Since then, ANDE has focused on building this evidence base 5.http://www.andeglobal.org/

6.ANDE is a global network of organisations that propel entrepreneurship in emerging markets by providing critical financial, educational and business support services to SGBs. 
and has a research team dedicated to proving this impact, as well as building their members' capacity to measure their own impact.

Khatuchi Khasandi, presenting on behalf of ANDE, described how ANDE seeks to measure impact to fulfil three main objectives:

- Create consistency: ANDE supports its members to adopt IRIS and maintain a core set of indicators to develop performance benchmarks.

- Communicate impact: ANDE collects data from members on an annual basis to produce sector-level reports.

- Knowledge sharing: ANDE hosts an annual 'Metrics from the Ground Up' conference and Metrics and Research Learning Labs, which are member-driven.

ANDE often hears from their member organisations that evaluation is expensive and time-consuming. However, ANDE carried out a survey amongst their member organisations and found that while $80 \%$ of them collect data, only $20 \%$ of them actually analyse this data. As a result, ANDE is pushing its members to move away from collecting large volumes of data towards collecting the right data, particularly data relating to the changes experienced in people's lives using consistent metrics like IRIS (Khatuchi Khasandi, presenting at the 8th AfrEA Conference 2017).

ANDE argues that there is a need for knowledge sharing between evaluators and investors on how impact can be measured. For instance, some impact investors may think that the only option to evaluate impact is through randomised control trials (RCTs). Given the cost, scale and potential drawbacks of having to withhold interventions (e.g. in the form of products and services) from a group of people who would make up the control group or counterfactual, RCTs are not easily implemented in most impact investment portfolios. The misinformation that RCTs are the most rigorous option may prevent investors from embracing social impact measurement, especially where it is unethical or undesirable to randomly select a treatment and control group (Khatuchi Khasandi, presenting at the 8th AfrEA Conference 2017). Therefore, knowledge sharing between evaluators and investors offers opportunities to engage around the useful and exciting tools that go beyond a narrow focus on RCTs.

\section{Social impact measurement and the distribution of capital}

Innovations in Evaluation strand participant Susan de Witt is the Impact Bond Project Manager at the Bertha Centre for Social Innovation and Entrepreneurship, ${ }^{7}$ the first academic centre in Africa dedicated to advancing social innovation and entrepreneurship.

A theme emerging through De Witt's presentation is that social impact measurement has the potential to influence

7.The Bertha Centre was established as a specialised unit at the University of Cape Town's (UCT) Graduate School of Business in late 2011, in partnership with the Town's (UCT) Graduate School of Business in late 2011, in partnership with the
Bertha Foundation, a family foundation that works with inspiring leaders who are Bertha Foundation, a family foundation the the allocation of capital by improving on information asymmetries related to positive and negative externalities produced through investments. As social impact measurement produces evidence concerning these externalities, it is anticipated that investors will become more knowledgeable and more persuaded to invest capital to maximise financial, social and environmental returns jointly. In this way, social impact measurement has the power to catalyse and scale social impact, align public and private interest, and more effectively distribute capital.

However, in order for this potential to be realised, the Bertha Centre has identified the following four key issues that need to be addressed when designing and implementing innovative finance instruments (Bertha Centre for Social Innovation and Entrepreneurship n.d.):

- Impact measurement: Traditional structures often treat impact measurement as either a 'nice to have' (debt and equity) or a post-project calculation (grants) and not as an integrated part of the strategy of the company or as a key component of how capital is allocated and priced. It is essential to embed best practices, such as impact measurement, into the actual flow of capital in order to understand if impact is optimised.

- Mismatch: There is a mismatch between the principles that investors use to find and assess potential deals and the state of readiness of many organisations. Additionally, there is a mismatch between investors' investment expectations and the pricing many investees are willing to give. Finally, there is a mismatch between the type of capital available and what investees are looking for.

- Distribution: As in traditional finance, the distribution of impact capital needs strong intermediaries, especially when it comes to matchmaking between impact investors and enterprises as well as investment readiness support in order to develop high quality investment opportunities. Innovative service providers and entrepreneurs that operate on a market competitive basis are emerging on the continent.

- Life cycle: Life cycle support is one thing that is significantly missing in the African market, specifically working with organisations from the early stage grants through to late stage equity. This doesn't need to be one funder; instead, this can be a coordinated effort on the part of multiple funders. Unfortunately, however, this type of coordination is not present in the current market.

In order to fill the $\$ 2.5$ trillion funding gap to accomplish the SDGs, the need to attract higher amounts of private capital is greater than ever. There is therefore a need for real systemic shifts in how capital is allocated. In the realm of innovative finance, there are several mechanisms that can integrate social impact measurement into investment decisions and management. This occurs when the returns are dependent on the achievement of specific output and outcomes targets and the measurement of progress and achievement then triggers payments and return profiles; therefore, in this way, the investment of the management 
of the performance is entirely dependent on impact measurement. Therefore, these instruments are designed not to treat impact as a side effect but as a core component of capital allocation by changing the cost of capital and return, screening out potential participants, enabling outcomes to trigger payments and putting monetary value to outcomes that were previously not valued (Bertha Centre for Social Innovation and Entrepreneurship n.d.).

De Witt discussed two possible instruments (Susan de Witt presenting at the 8th AfrEA Conference 2017):

- Blended finance is a development finance model that combines concessionary loans or grants, usually provided by the public sector, with private investment. It aims to alleviate the development funding constraint by de-risking investments into the sector and directing more private capital towards projects or geographies that would otherwise be perceived as too risky for traditional investors.

- Social impact bonds are a financial mechanism that operates on the basis of paying for outcomes as opposed to inputs. There are alternate ways of paying for outcomes-based contracts, where investors provide capital to underwrite social projects usually funded by tax money and philanthropists. If a project is successful as measured against pre-agreed benchmarks, the investor gets a return on the economic value created for government. On the other hand, if the project is not successful, investors lose their money.

\section{How can impact measurement catalyse capital?}

Independent third-party standards that are used by businesses, investors and institutions for defining, measuring and comparing positive social and environmental impact allow users to manage their impact, as well as the impact of the businesses with whom they work, thereby enabling attraction of mainstream capital (Honeyman 2014).

During the Innovations in Evaluation strand, Olivia Muiru, the director for B Lab East Africa, ${ }_{1}^{8}$ stressed the need and importance for such standards, without which there are significant barriers to scale in the impact investing space, including a fragmented market where each investor defines impact differently, faces high due diligence and transaction costs, has a limited understanding of how to manage impact and faces a weak policy environment because of a dearth of information (Concord Advisory Group n.d.).

Moreover, without such standards, there exists a lack of a standard common language to talk about results, the lack of transparency and credibility in how funds define, track and report the social and environmental performance of impact investors' portfolios, or the ability of investors to compare investments and aggregate information across a portfolio. The market is faced with a scarcity of consistent, credible non-financial performance information, which also inhibits 8.https://ib-labeastafrica.net/ comparisons between impact investing opportunities, development of social and environmental performance benchmarks, and other aggregate industry analyses.

One such standard is the B Impact Assessment ${ }^{9}$ used by forprofit organisations, created by B Lab, which has been used by a wide array of businesses worldwide, ranging from investment advisers to healthcare providers. The B Impact Assessment ${ }^{10}$ is a free online, easy-to-use, standardised measurement and management tool for impact performance. Depending on their size and industry sector, companies are asked between 60 and 170 questions that consider their operational impact and assess their performance across the following five impact areas:

- customers

- governance

- workers

- community

- environment.

Once a company has scored a minimum of 80 out of 200 on the B Impact Assessment, they then become Certified B Corporations. ${ }^{11}$

Through the B Impact Assessment, B Lab provides the impact standards and rating system necessary to facilitate a scalable and transparent marketplace for institutional investors, financial services intermediaries and companies seeking mission-aligned growth capital. Through the development and use of such third-party assessments, transparency, credibility and accountability will be supported in impact measurement practices across the impact investing industry.

\section{The value proposition of social impact measurement for small and growing businesses}

Khatuchi Khasandi, of ANDE, demonstrated the role that SGBs play in the economic growth of a country. Small and growing businesses are defined by ANDE as commercially viable businesses, with 5-250 employees, that have significant potential, and ambition, for growth. Typically, SGBs seek growth capital from $\$ 20000$ to $\$ 2$ million (ANDE 2016). Aspen Network of Development Entrepreneurs has identified that SGBs differ from the more traditional characterisation of small and medium enterprises in two fundamental ways: Firstly, SGBs are different from livelihood-sustaining small businesses, which start small and are designed to stay that way; secondly, unlike many medium-sized companies, SGBs often lack access to the financial and knowledge resources 9.https:///bimpactassessment.net/

10.The B Impact Assessment was created by an independent Standards Advisory Council, staffed by B Lab, which is formed of a group of independent experts in business and academia who are also responsible for revising the standards. The assessment is updated every 2 years in order to accommodate new and innovative assessment is updated every 2 years in order to accommodate new and innovative practices, respond to the feedback of its users and to more accurately assess the
impact of all types of businesses.

11.The ' $\mathrm{B}$ ' in 'B Corporations' stands for beneficial and indicates that the certified organisations voluntarily meet certain standards of transparency, accountability, sustainability and performance, with an aim to create value for society, not just for traditional stakeholders such as the shareholders. 
required for growth, such as human capital, access to finance, access to markets.

According to ANDE, as SGBs attain investments, their growth results in the creation of jobs, thus generating a multiplier effect on the local economy through wages and training. In addition to this, SGBs have the potential to provide goods and services to communities that otherwise were not able to access or afford them. Small and growing businesses are therefore seen by many impact investors (and indeed policymakers) as perfectly positioned to stimulate long-term economic growth, produce environmental and social benefits and ultimately lift countries out of poverty.

Given this focus on SGBs amongst impact investors, it is important that impact measurement approaches are designed with their specific characteristics, capacity and interests in mind. For instance, impact measurement has to be 'right sized' to be feasible for businesses that are likely to have a small target client market and small-scale operations. This means that data collection efforts cannot be too expensive or time intensive or impact measurement will not be practical.

Additionally, because SGBs face barriers in accessing knowledge resources that are useful for growth, a clear value proposition for impact measurement is the use of information produced through their activities for their internal learning in order to improve operations or scale the business. As an example, an impact study for an SGB concerning the ways that clients use their products and what kind of changes clients experience might assist them with business intelligence that can be applied to their sales or marketing strategy while also communicating their impact to stakeholders on the communities that they operate in. In this way, if there is a clear value proposition it might be possible to improve the buy-in amongst SGBs to contribute to and facilitate impact measurement activities.

\section{The movement towards lean data}

Expanding on the theme of 'evaluation that creates value for participants' that was forthcoming during discussions around the SGBs, it is also important that this value not be diminished by over-scoped impact measurement activities.

Ashely Speyer, from Acumen's Lean Data team, ${ }^{12}$ described the need for a shift to be 'lean' in data collection. 'Lean' as an industrial philosophy has been around for some time, originating in manufacturing, and focuses on the use of techniques and principles with the aim of a reduction in waste (Womack \& Jones 2003).

Research conducted by the Harvard Business School in 2015 (So \& Staskevicius 2015) found that, globally, the most 12.http://acumen.org/ideas/lean-data/ common factors that contribute to low incentives to measure impact amongst social enterprises include the following:

- limited time and resources that are needed to allocate to extensive impact measurement

- the recognition of survey fatigue amongst beneficiaries

- for those social enterprises that do have some measurement in place, their main focus is maximising their financial return while meeting the impact threshold, and therefore they do not value robust measurement.

Research was undertaken by ANDE in 2014, and again in 2017, in order to better understand measurement practices in the SGB sector and to help organisations benchmark themselves against their peers. During this research, 30 ANDE members were surveyed about their measurement practices. The findings of the survey were captured in a report titled The State of Measurement in the Small Growing Business Sector. The reports highlighted that the measurement of impact is relatively under-resourced amongst organisations based in sub-Saharan Africa. Of the six Africa-based organisations who responded, only one had a full-time staff member dedicated to measurement (Edens \& Lall 2014). The report also identified that according to members of ANDE's Metrics Learning Labs in East and South Africa, the greatest challenge to measurement is not cost but deciding what and how to measure, collecting data, and complexity resulting from lack of centralised methods and standards (Edens \& Lall 2014; Losoya- Evora \& Edens 2017).

Given these challenges and constraints faced by social enterprises, including their lack of technical capacity in impact measurement, and the fact that one of the primary functions involved in measuring impact is the collection of data, impact investors need to continue to develop their understanding of how their investments are affecting households and how to better allocate capital, while at the same time recognising these challenges. As a result, by applying the lean philosophy framework to monitoring results and information management, Acumen ${ }^{13,14}$ established the Lean Data initiative. This uses new technologies to gain information about customers more time- and cost-efficiently, yielding powerful business insights and ideas about how products, services and programmes can be made more meaningful for customers.

Acumen is encouraging their investees to adopt Lean Data and collect data on their impact by leveraging mobile phones and associated technologies; applying rapid survey questionnaires; and integrating the collection, analysis and use of data into the enterprises internal processes. Specifically, through the Lean Data approach, measurement amongst entrepreneurs is moving from:

- Compliance to collaboration: Lean Data approaches are responsive to context, and the measurement approach and collection tools are tailored to the unique context of

\section{3.https://acumen.org/}

14.Acumen is an impact investing fund that was founded in 2001 that invests patient capital in enterprises across Africa, Asia, Latin America and Northern America. 
each organisation and designed to collect data that answers the questions they care about the most.

- Putting the investor first to putting the customer first: The Lean Data approach creates the space to hear from customers to help entrepreneurs provide more impactful products or services by asking questions such as 'what data will help the enterprise better serve the customer?'

- Reporting requirements to better business decision-making: Lean Data projects serve the dual function of measuring performance while creating a recurring stream of customer information that can be used to make betterinformed business decisions.

- Resource-heavy and expensive to time-efficient and costefficient: By leveraging technology -SMS, integrated voice response and call centres - high quality data can be gained as close to real time as possible without spending a lot of money. Moreover, costs of data collection are proportionate to the value of performance monitoring.

Through the Lean Data initiative, Acumen hopes that all data within an organisation's information landscape will in some way be linked to creating value for the end customer and the organisation's objectives - whether this is revenue maximisation, cost reduction or something else. Therefore, Lean Data can be suited to social enterprises that face the dual pressure of time and cash constraints but still need real data to know that they are delivering on their social, environmental and financial objectives.

\section{The importance of client-centricity}

Understanding the needs of customers is critical in the pursuit of social impact. Without better information on the positive or negative impact of a product or service, an enterprise's ability to maximise its impact is limited (Adams, Ripley \& Speyer 2017; Social Performance Taskforce 2016; Van Den Driest, Sthanunathan \& Weed 2016). In seeking to measure or evaluate the changes as a result of interactions with a particular social enterprise, investment or participation in a programme, evaluations may extract data from disadvantaged communities without providing any benefit in return. This can reinforce actual and perceived imbalances in power and opportunity between the people conducting the research and the people being studied. It can then be said that the very methods of evaluation can threaten to reentrench the power dynamic that market-based approaches to development seek to mitigate in the first place.

There is therefore a need for client-centric evaluation, or evaluation that provides a way for practitioners to balance their commitment to holding themselves accountable to their mission and commitment to embody values of equality, empathy and mutual respect for the disadvantaged populations with whom they work.

An example of good practice of client-centric evaluation is that which is conducted by Root Capital ${ }^{15}$ - an agricultural 15.https://rootcapital.org/ impact investor with a mission to promote rural prosperity across 26 vulnerable countries across Africa, Asia and Latin America by lending capital, delivering financial training and strengthening market connections for small and growing agricultural businesses. ${ }^{16}$

Root Capital's results chain maps the outcomes they intend their investments to achieve (Figure 4).

The primary hypotheses that Root Capital seeks to test are that agricultural businesses enable farmers to achieve higher and more stable incomes over the long term through increased prices for their crop, improved farm productivity and increased stability of market access. In return, these farmers provide a reliable supply of high quality, sustainably produced agricultural product to the businesses, and ultimately to consumers.

Root Capital conducts deep-dive studies with a subset of investees representative of their global portfolio in order to evaluate whether and how their client agricultural businesses support farmers' livelihoods. While conducting these deepdive studies, Root Capital's guiding principle is 'clientcentric evaluation', which seeks to generate the impact data needed on small-scale farmers in order to create value both for the farmers and for the enterprise. This means that rather than measuring impact as impartial outside observers, Root Capital seeks to observe and measure impact as value-added partners who help farmers and enterprises to increase the value provided to the other.

However, the client-centric approach to evaluation is not without its trade-offs, and, for example, it has the disadvantage of being less objective than experimental evaluations. Yet, for some clients for whom experimental evaluations are operationally infeasible or are simply too costly, a client-centric approach enables the engagement of clients that might not otherwise participate in impact evaluations. In cases where experimental evaluations are possible, on the other hand, a client-centric approach maximises the chance that a potentially interested client will feel comfortable proceeding as a research object. Moreover, a client-centric approach may also improve the quality of the impact data that can be obtained by focusing the study design on issues that are of true importance to the participants and their communities and thereby increasing the commitment level of these participants. This means that client-centricity is more likely to elicit honest and representative responses from clients.

In addition to the deep-dive studies, Root Capital assesses impact through social and environmental scorecards. These scorecards are portfolio-wide measurements based on data from the social and environmental due diligence that is conducted with all of their clients (potential and existing) to ensure their clients' objectives are aligned to Root Capital's

16.Root Capital's lending facility makes loans to rural grass-roots enterprises, such as organic coffee and cocoa cooperatives, handcraft associations, wild-harvested nut producers and ecotourism businesses. 


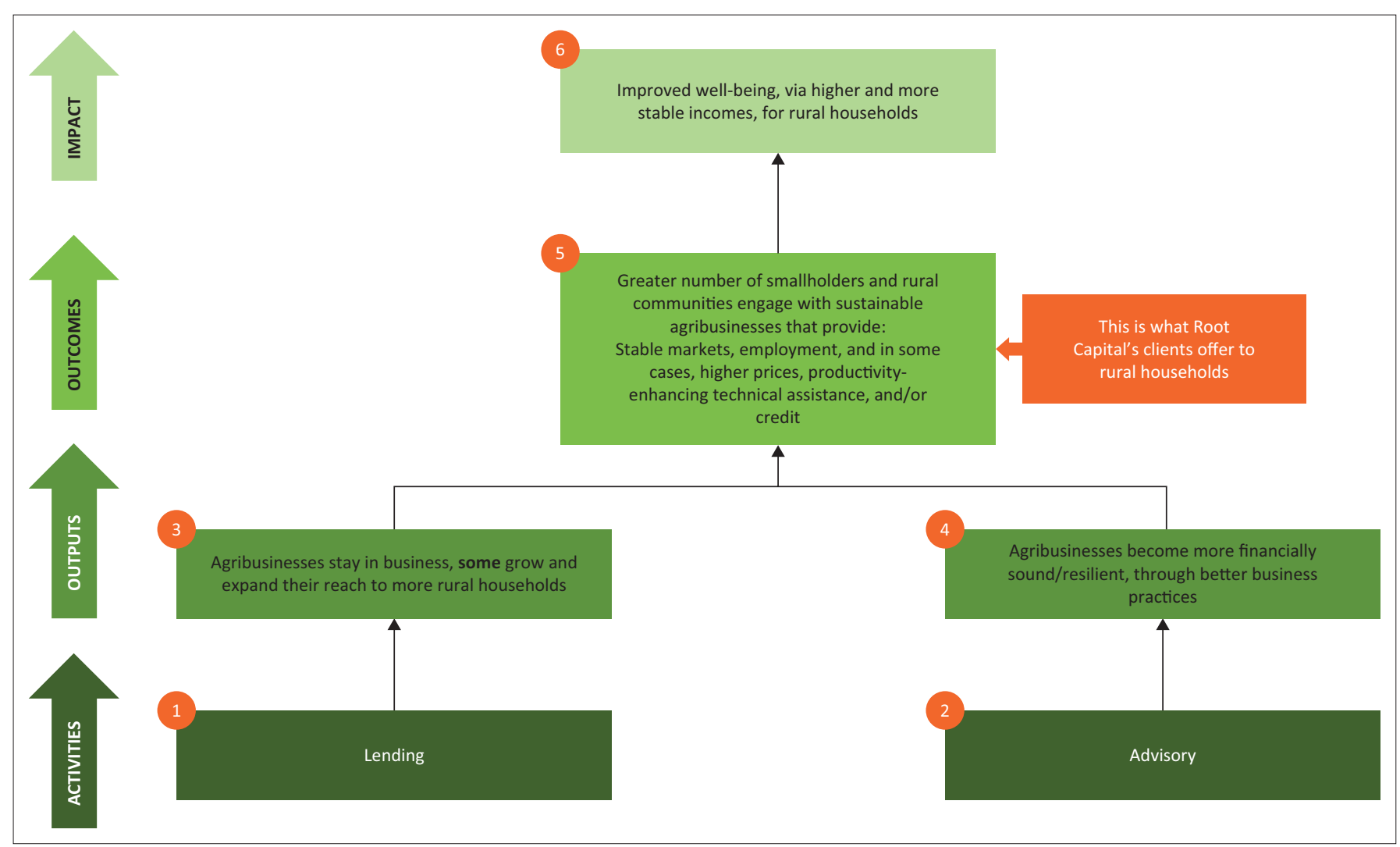

Source: Innovations For Poverty Action, n.d., Root Capital, viewed 27 May 2018, from https://www.poverty-action.org/sites/default/files/publications/goldilocks-toolkit-root-capital-casestudy_2.pdf

FIGURE 4: Root Capital's theory of change.

vision. The scorecards act as both a negative screen for harmful social and environmental practices, as well as a positive screen to establish potential impact using proxies that Root Capital corroborates during impact studies. The social and environmental scorecards act as a loan-level decision-making through impact rating (combining social and environmental metrics) and to assess investment and the financial return of loans.

\section{Closing the gap on social impact measurement}

While impact investors and measurement and social sector actors share the same overarching goals, specifically the contribution to positive social change, the measurement practices of these stakeholders are independent - as two parallel streams with little crossover (Reisman, Gienapp \& Kelly 2015). Participants of the Innovations in Evaluation strand offered several thoughtful comments on the differing measurement practices amongst these actors and what needs to occur in order to close this gap.

In the development space, there is a premium placed on collecting and conducting analysis of data around meaningful changes in life, and the evidence of outcomes and impact on people's lives. On the other hand, investors' measurement is focused on the number of lives touched or people reached and is limited to the output level. In addition to this, the measurement has been at the pre-investment phase and hence the focus has been on measuring the potential for impact.

The group identified that impact investors seem to be more quantitative in their approach to social impact measurement, which is why it is often difficult for them to define outcomes and impact. While the field of development evaluation continues to place a premium on attribution, as the field has matured there is a greater appreciation amongst development practitioners as well as impact investors around the fact that understanding attribution is hard, costly and seldom possible. As a result, there is a greater acceptance of information about contribution, as demonstrated by the case of Root Capital.

Development evaluation has become a mature field, with an older, experienced membership. Evaluators have therefore spent a lot of time developing and using various tools and approaches to evaluation. Impact measurement, on the other hand, is an early stage area of practice with younger members, technology-driven tools and a market-oriented stance. Impact investors, who are new to this space, recognise that evaluation is often costly and difficult. Therefore, there is opportunity for complementarity, synergy and collaboration between these two groups of stakeholders, and evaluative tools and approaches need to be made available and accessible so that they can be incorporated into design in the measurement of impact investing efforts. 
Given this environment, evaluators can offer their useful and exciting tools, including strong qualitative data collection and analysis skills, with a particular view to exposing negative or unintended consequences of a programme or product, to impact investors, that go beyond a narrow focus of RCTs, which were identified by participants in the strand as the 'gold standard' for achieving the rigour of attributing impact above any other forms of impact measurement method.

Lastly, participants in the Innovations in Evaluation strand identified what investors and evaluators can agree on and came up with the following:

- Impact investors and evaluators need to learn about one another's context.

- Clarity of the different concepts is also needed: what is an outcome? What is impact?

- The need for more engagement and continued dialogue between impact investors and evaluators was also identified; consistent dialogue is important to know what issues are hampering the two groups of stakeholders from converging.

\section{Conclusions}

Impact investing, defined as investments made into companies, organisations and funds with the intention to generate social and environmental impact alongside a financial return, is an emerging field that has grown rapidly in the last few years, outside international development. This growth has produced an unprecedented focus on measuring the social impact resulting from these investments, based on the recognition that there is a need to understand the financial and social return of innovative finance; because this is a relatively new industry, data on activity and performance can play an important role in developing and helping to grow the industry.

The Innovations in Evaluation strand at AfrEA enabled a breadth and depth of conversation between stakeholders in the impact investing space in Africa and allowed for convergence between these stakeholders. This article reported on these conversations and provided examples of organisations practising social impact measurement methods, each of which contribute to building evidence about impact measurement, both globally and on the African continent. A discussion on the need for social impact measurement to feature voices of their beneficiaries or customers and the broader communities within which they operate was also undertaken.

Lastly, this article promoted a convergence of methods, building from both the impact investment and evaluation fields. There was consensus amongst participants in the strand that the evaluation profession has much to offer to overcome the challenges inherent in social impact measurement, in order for the field to accelerate further. However, in order for this to be realised, there needs to be continued conversations, deep understanding of the interests of various stakeholders and the skills and willingness to explore customisation and innovation of existing evaluation approaches and methods. It is important that, as the discussions and efforts to strengthen the evidence base for impact investing take place, the African impact investing landscape is represented and the experiences of stakeholders in Africa are included in these conversations and platforms that aim to solve fragmentation and support the social impact measurement, for example the GIIN's Impact Toolkit and the Impact Management Programme. This is important to consider cultural and contextual factors that are specific to the African continent and hence local solutions for local challenges to impact measurement. With the global focus on impact investing, which must be founded on social impact measurement, the drive to develop measurement further is also likely to continue, or accelerate.

A key stakeholder voice that was missing during the Innovations in Evaluation strand at the AfrEA conference was that of investors and, as a result, investors' perspectives were included in the strand based on evaluation practitioners' experiences. Therefore, more needs to be done to encourage the convergence of impact investors and investees, such as through neutral convening spaces like ANDE's Learning Labs.

\section{Acknowledgements Competing interests}

We declare that we have no financial or personal relationships that may have inappropriately influenced us in writing this article.

\section{Authors' contributions}

A.C. and M.T. contributed equally to this article.

\section{References}

Adams, T., Ripley, M. \& Speyer, A., 2017, At the heart of impact measurement, listening to customers, viewed 27 May 2018, from https://ssir.org/articles/entry/ at_the_heart_of_impact_measurement_listening_to_customers

ANDE, 2016, State of small and growing business sector 2016 impact report, viewed 27 May 2018, from https://c.ymcdn.com/sites/www.andeglobal.org/resource/ resmgr/Research_and_Impact_updates/2016_SOTS_Report.pdf

Bannick, M. \& Goldman, P., 2012, Priming the pump: The case for a sector based approach to impact investing, viewed 23 May 2018, from http://tinyurl.com/ jhnjm6b

Bertha Centre for Social Innovation and Entrepreneurship, n.d., Innovative finance in Africa review, viewed 27 May 2018, from http://www.gsb.uct.ac.za/Downloads/ InnovativeFinanceAfrica_1.pdf

Concord Advisory Group, n.d., Impact investing, establishing a framework from idea to implementation, viewed 27 May 2018, from http://www.concordadvisory.com/ sites/concordadvisory.com/files/market-reviews/Impact\%20lnvesting_0.pdf

Costa, E. \& Pesci, C., 2016, 'Social impact measurement: Why do stakeholders matter?', Sustainability Accounting, Management and Policy Journal 7(1), 99-124, viewed 27 May 2018, from https://www.emeraldinsight.com/doi/full/10.1108/ SAMPJ-12-2014-0092

Edens, G. \& Lall, S., 2014, The state of measurement practice in the SGB sector, viewed 27 May 2018, from https://c.ymcdn.com/sites/www.andeglobal.org/resource/ resmgr/Files/The_State_of_Measurement_Pra.pdf

European Union \& OECD, 2015, Policy brief on social impact measurement for social enterprises, viewed 27 May 2018, from https://www.oecd.org/social/PB-SIMWeb_FINAL.pdf

GIIN, 2015a, The landscape for impact investing in East Africa, viewed 23 May 2018 from https://thegiin.org/assets/documents/pub/East $\% 20$ Africa $\% 20$ Landscape $\% 20$ Study/05Kenya_GIIN_eastafrica_DIGITAL.pdf 
GIIN, 2015b, The landscape for impact investing in West Africa, viewed 23 May 2018 from http://ventureburn com/wp-content/uploads/2015/12/GIIN-West-AfricaRegional-Report-2015-vFINAL-1.pdf

GIIN, 2016, The landscape for impact investing in Southern Africa, viewed 23 May 2018, from https://thegiin.org/assets/documents/pub/Southern\%20Africa/GIIN SouthernAfrica.pdf

Graduate School of Business, 2018, Responsible investors channel over $\$ 400$ billion into Africa, University of Cape Town, viewed 27 May 2018, from http://www.gsb. uct.ac.za/po-impact-investing-barometer

Honeyman, R., 2014, Has the B corp movement made a difference?, viewed 27 May 2018, from https://ssir.org/articles/entry/has_the_b_corp_movement_made_a_ difference

IDEAS, 2017, Evaluation for agenda 2030, viewed 23 March 2018, from https://ideasglobal.org/evaluation-for-agenda-2030/

Innovations For Poverty Action, n.d., Root Capital, viewed 27 May 2018, from https:// www.poverty-action.org/sites/default/files/publications/goldilocks-toolkit-rootcapital-case-study_2.pdf

Khatuchi Khasandi, 2017, 'ANDE Metrics Learning Lab', presenting at the 8th AfrEA International Conference 2017, 29-31 March 2017, Kampala, Uganda.

KPMG International, 2016, Unlocking the power of partnership, viewed 27 May 2018, from https://assets.kpmg.com/content/dam/kpmg/pdf/2016/01/unlocking-powerof-partnership.pdf

Losoya-Evora, B. \& Edens, G., 2017, State of measurement in the SGB sector, viewed 27 May 2018, from https://cdn.ymaws.com/www.andeglobal.org/resource/ resmgr/metrics/2017_documents/State_of_Measurement_in_the_.pdf

Lynch, K., 2015, The impact investing illusion, viewed 27 May 2018, from https://www.huffingtonpost.com/kevin-lynch/the-impact-investing illusion_b_8671024.html

Maas, K. \& Liket, K., n.d., 'Social impact measurement: Classification of methods', PhD paper, Department of Business Economics, Erasmus University Rotterdam.

McCreless, M., Fonzi, C.J., Edens, G. \& Lall, S., 2014, Metrics 3.0: A new vision for shared metrics. Stanford social innovation review, viewed 23 March 2018, from $\mathrm{https}$ ://ssir.org/articles/entry/metrics_3.0_a_new_vision_for_shared metrics

Mudaliar, A., Pineiro, A., Bass, R. \& Dithrich, H., 2017, The state of impact measurement and management practice. Global impact investing network, viewed 23 March 2018, from https://thegiin.org/research/publication/imm-survey

Niculescu, M., 2017, Impact investment to close the SDG funding gap, viewed 23 March 2018, from http://www.undp.org/content/undp/en/home/blog/2017/7/13/ what-kind-of-blender-do-we-need-to-finance-the-sdgs-.htm

OECD, 2015, Social impact investment: Building the evidence base, viewed 27 May 2018, from https://read.oecd-ilibrary.org/finance-and-investment/social-impactinvestment_9789264233430-en\#page15

Reeder, N., Colantonio, A., Loder, J. \& Jones, G.M., 2015, 'Measuring impact in impact investing: An analysis of the predominant strength that is also its greatest weakness', Journal of Sustainable Finance \& Investment 5(3), 136-154, viewed 23 May 2018, from https://www.tandfonline.com/doi/abs/10.1080/20430795.2 015.1063977
Reisman, J. \& Olazabal, V., 2016, Situating the next generation of impact measurement and evaluation for impact investing, viewed 27 May 2018, from measurement and evaluation for impact investing, viewed 27 May 2018, from Measurement-Landscape-Paper-Dec-2016.pdf

Reisman, J., Gienapp, A. \& Kelly, T., 2015, A formula for change, Working paper, ORS Impact, viewed 27 May 2018, from http://orsimpact.com/wp-content/ uploads/2015/11/12L2 LAYOUT FINAL.pdf

Seitz, T., 2018, The spectrum of impact investing, viewed 23 May 2018, from https:// medium.com/impact-engine/the-spectrum-of-impact-investing-e34b0e4dc164

So, I. \& Staskevicius, A., 2015, Measuring the 'impact' in impact investing, MBA Report, Harvard Business School Social Enterprise Initiative, Harvard College, viewed n.d. from http://www.hbs.edu/socialenterprise/Documents/Measuringlmpact.pdf

Social Impact Investment Taskforce, 2014, Based on measuring impact: Subject paper of the impact measurement working group, viewed 27 May 2018, from https://www.thinknpc.org/publications/impact-measurement-working-group measuring-impact/imwg_measuring-impact-3/\%3Fpost-parent $\% 3 \mathrm{D} 11778+\& \mathrm{~cd}=$ $1 \& \mathrm{hl}=\mathrm{en} \& \mathrm{ct}=\mathrm{clnk} \& \mathrm{gl}=\mathrm{ke}$

Social Performance Taskforce, 2016, Interview with Frank DeGiovani: Reflections on 10 years of social performance task force, viewed 27 May 2018, from https:// us12.campaign-archive.com/?u=8c812b797a2f9ded471a394cd\&id=a8e21f1a69 $\& e=c 17028 a 1 b 1$

Susan de Witt, 2017, 'Overview of innovative finance in Africa' presenting at the 8th AfrEA International Conference 2017, 29-31 March 2017, Kampala, Uganda.

The New Media Group, n.d., The global impact investing ratings system, viewed 27 May 2018, from http://thenewmediagroup.co/the-global-impact-investingratings-system/

Rockefeller Foundation, 2012, Accelerating impact achievements, challenges and what's next in building the impact investing industry, viewed 27 May 2018,
from https://assets.rockefellerfoundation.org/app/uploads/20120707215852/ Accelerating-Impact-Full-Summary.pdf

Tuan, M., 2008, Measuring and/or estimating social value creation: Insights into eight integrated cost approaches, viewed 27 May 2018, from https://docs. gatesfoundation.org/documents/wwl-report-measuring-estimating-social-valuecreation.pdf

United Nations Development Programme, 2016, Impact investment in Africa: An action plan, viewed 27 May 2018, from http://www.undp.org/content/dam/undp/ library/corporate/Partnerships/Private $\% 20$ Sector/Impact $\% 20$ Investment $\% 20$ in $\% 20$ Africa/Impact $\% 20$ Investment $\% 20$ in $\% 20$ Africa $\% 20$ Action $\% 20$ Plan $\% 20$ version $\% 2023 F e b 2016$ clean.pdf

Vaca, S. \& Dhillon, L., 2016, 'Innovations in presenting theory of change', in Evaluation 2016 conference, Atlanta, GA, October 24-29, 2016, viewed n.d., from http:// www.saravaca.com/wp-content/uploads/2016/12/Presenting-ToC-LovelyDhillon-Sara-Vaca-2016.pdf

Van Den Driest, F., Sthanunathan, S. \& Weed, K., 2016, Building and insights engine, viewed 27 May 2018, from https://hbr.org/2016/09/building-an-insights-engine

Wilson, K., 2016, Investing for social impact in developing countries, The sustainable development goals as business opportunities, OECD publishing, viewed 27 May 2018, from https://papers.ssrn.com/sol3/papers.cfm?abstract_id=3125707

Womack, J.P. \& Jones, D.T., 2003, Lean thinking, Simon \& Schuster, London. 